\title{
Treacher Collins Syndrome: A Case Report
}

\author{
Niharika Kumari ${ }^{1}$, Gopa Kumar R Nair ${ }^{2}$, Vinay Mohan ${ }^{3}$, Anuj Gaur ${ }^{4}$, \\ Kalpana Poudel $^{5}$, Binish Khan ${ }^{6}$, Ngurang Anam ${ }^{7}$ \\ 1,5,6,7 Post Graduate Student, ${ }^{2}$ Professor \& H.O.D, ${ }^{3}$ Professor, ${ }^{4}$ Reader, \\ Department of Oral Medicine and Radiology, K.D Dental College and Hospital, Mathura, Uttar Pradesh
}

Corresponding Author: Niharika Kumari

\begin{abstract}
The Treacher Collins syndrome (TCS), also known as mandibulofacial dysostosis or Franceschetti-Zwahlen-Klein syndrome. Treacher Collins syndrome (TCS) is related to atypical differentiation of the first and second pharyngeal arches, taking place during fetal development. Prevalence of this syndrome is approximately 1 in 50,000 live births and it affects both genders equally. This article describes clinical and radiographic features of TCS who had reported to the department of Oral Medicine and Radiology with the complaint of multiple dental caries. Also diagnosis, differential diagnosis, management and preventive aspects are discussed.
\end{abstract}

Keywords: Treacher Collins syndrome, TCS, mandibulofacial dysostosis, Franceschetti-

Zwahlen-Klein syndrome

\section{INTRODUCTION}

Treacher Collins syndrome (OMIM number 154500) is a craniofacial development of autosomal dominant condition. It affects one out of every 50,000 live births. Thomson first described this condition in 1846, and George Andreas Berry (1889) later described it as a congenital neonatal deformity with colobomata of the lower eyelids. The essential components of the syndrome were illustrated by Edward Treacher Collins (1900), an ophthalmologist after whom the disorder was named. This condition is also known as mandibulofacial dysostosis (MFD) and Franceschetti-Zwahlen-Klein
(Franceschetti and Klein) (Franceschetti and Klein). (1, 2, 3, 4. 5)

Changes in embryo development of the first and second gill arches during the fifth and eighth weeks of foetal development cause abnormal craniofacial development. (5) Mutations in the TCOF1 and POLR1D genes cause Treacher Collins Syndrome. TCOF1 or POLR1D have autosomal dominant inheritance, whereas POLR1C has autosomal recessive inheritance. (6) Antimongoloid palpebral fissures, malar and mandibular hypoplasia, auricular pinna malformation, coloboma of the lower eyelids, conductive deafness, cleft palate, and dental anomalies are the most common clinical symptoms. These individuals' quality of life can be improved by early detection and treatment. (4)

\section{CASE REPORT}

A 7 year old boy reported to the Department of Oral Medicine and Radiology, K.D. Dental College and Hospital, Mathura; complaining of multiple carious teeth. Genealogical examination revealed that the patient was the second child born to a non consanguineous healthy parents via vaginal delivery with normal Appearance, Pulse, Grimac Activity and Respiration (APGAR) score. The only elder sibling didn't have any comparable complaints. He was 3 feet and 5 inch tall and $14 \mathrm{~kg}$ in weight. Also, there was no history of allergy with normal IQ level. Patient was ectomorphic with mesoproscopic face form. He presented with 
Dolicopcephalic head with frontal bossing and hypertelorism. Malformation of auricular pinna was evident. Antimongloid slant of palpebral fissure with coloboma of the eyelid was observed. Sparseness of eyelashes in the middle and mesial third of the lower eyelid was also noticed. The patient also exhibited decreased prominence of middle third of face due to malar hypoplasia and underdeveloped zygoma with micrognathic Mandible, giving an overall appearance of a "bird face".

Intraoral finding revealed high arched V shaped palate, micrognathia,

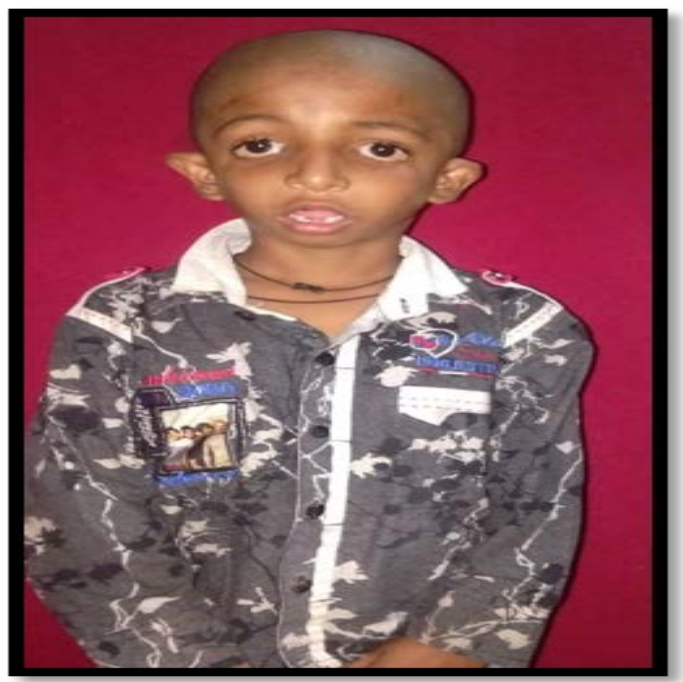

Extraoral view showing frontal bossing, hypertelorism, hypoplastic malar region and underdeveloped zygoma

- Antimongloid slant of palpebral fissure

- coloboma of the eyelid

- Sparseness of eyelashes in the middle and mesial third of the lower Eyelid.

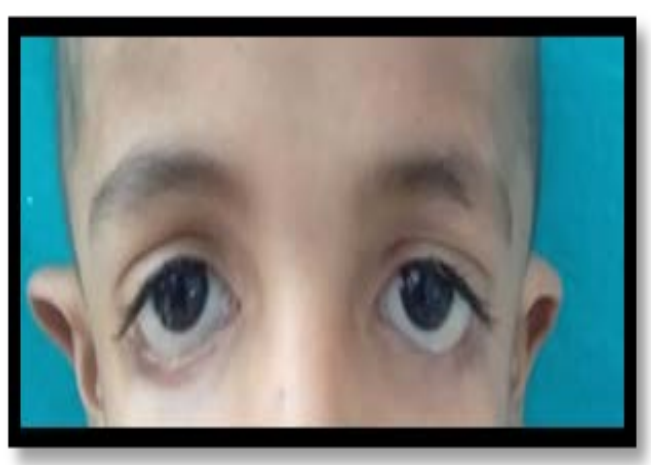

microstomia, incompetent lips, open bite, carious teeth in relation to $54,64,74,82,84$, root stumps in relation to $51,52,61,62,71,81$. IOPAR revealed periapical lesion in relation to 74. Orthopantamograph showed mixed dentition with developing tooth buds and root stumps as seen clinically. Lateral cephalogram showed underdeveloped zygoma, prominent nose and anterior open bite. Posteroanterior skull view showed hypoplasia of Maxilla. A diagnosis of Treacher Collin Syndrome was made based on the history, clinical and radiographical features.
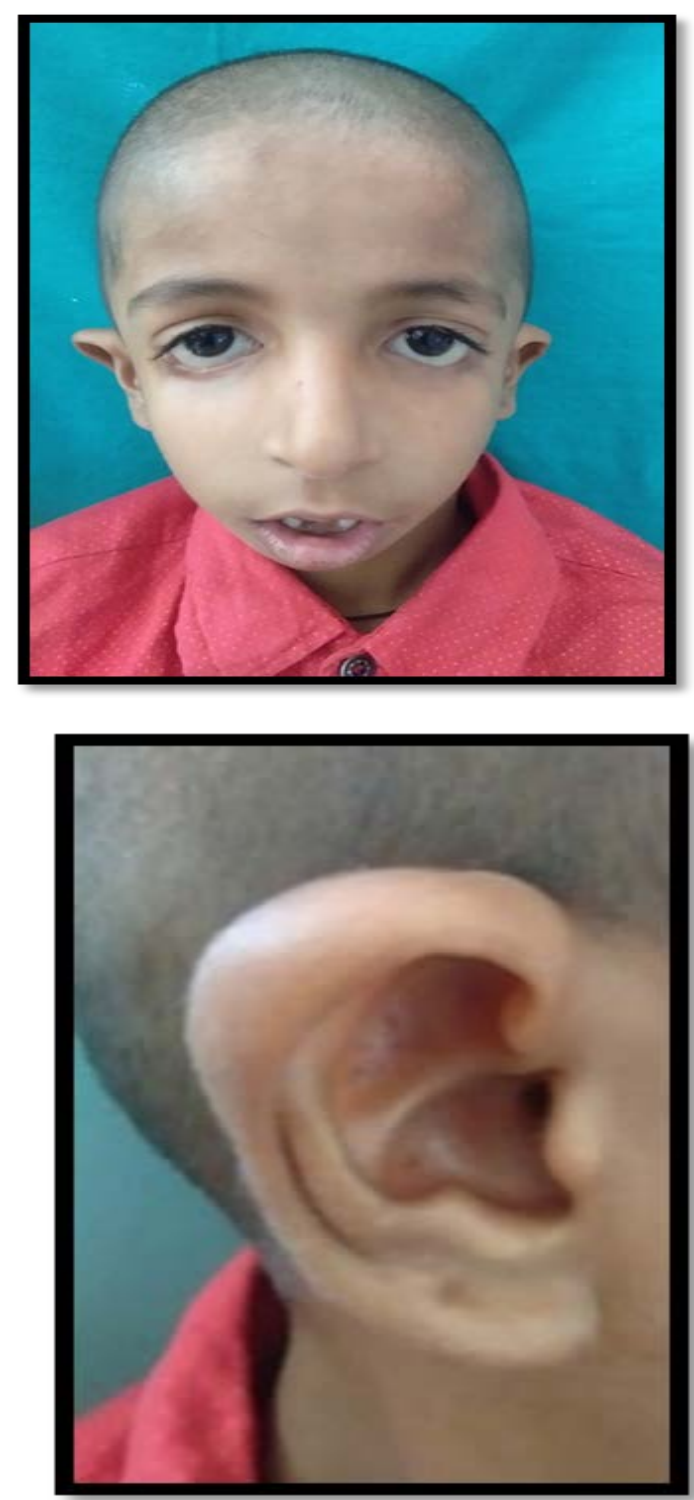


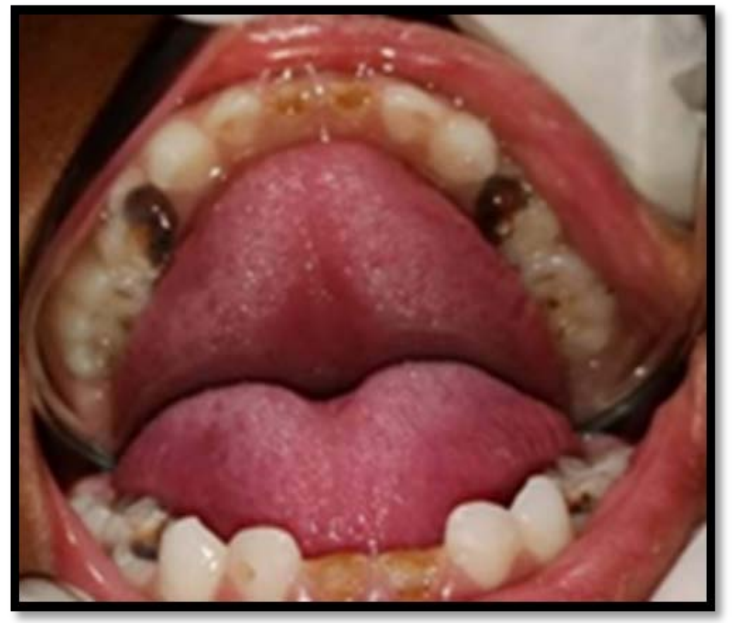

Malformation of auricular pinna

Intraoral picture showing high arched $\mathrm{V}$ shaped palate, multiple root stumps and carious teeth

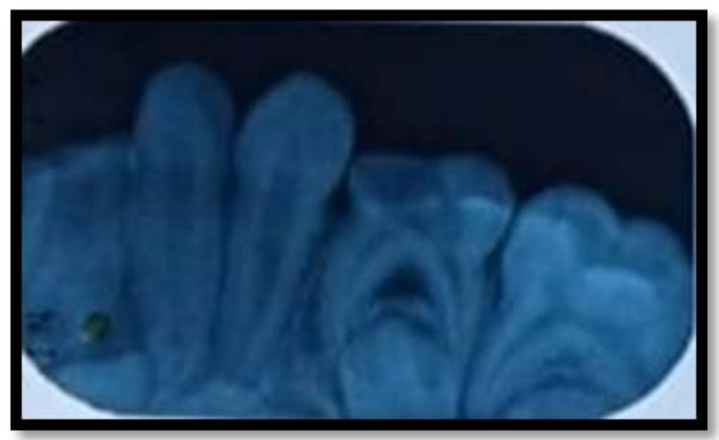

IOPAR showing caries in relation to 74

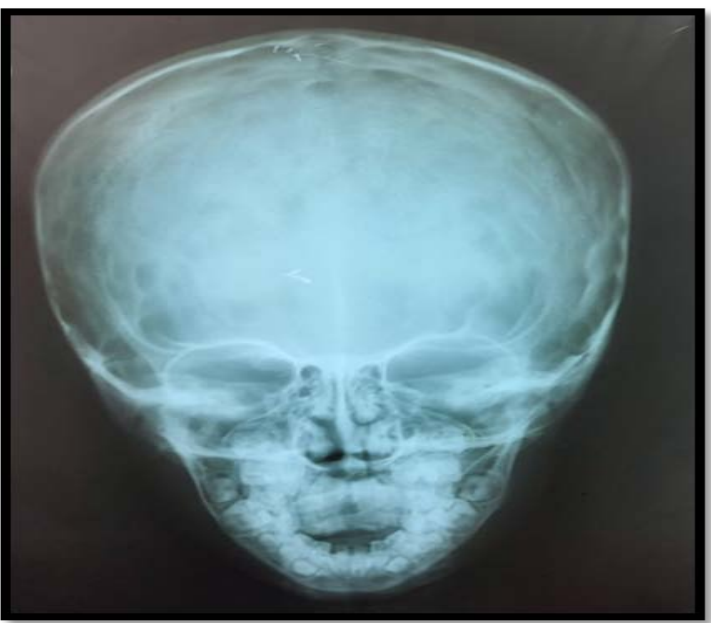

PA skull showing hypoplasia of Maxilla

Lateral cephalogram showing underdeveloped zygoma, anterior open bite and prominent nose

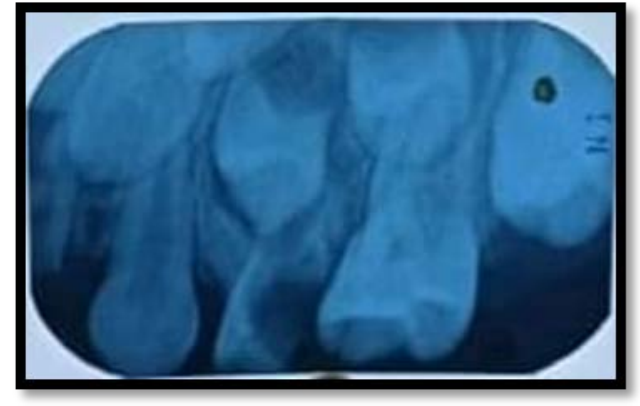

IOPAR showing periapical lesion wrt 64

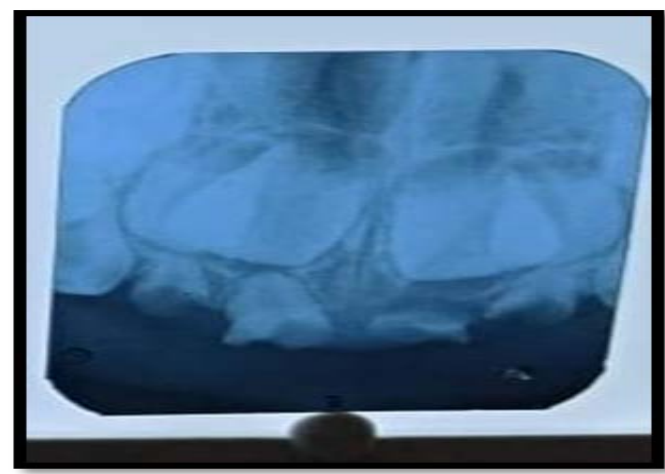

IOPAR showing root stump wrt 51,52,61,62

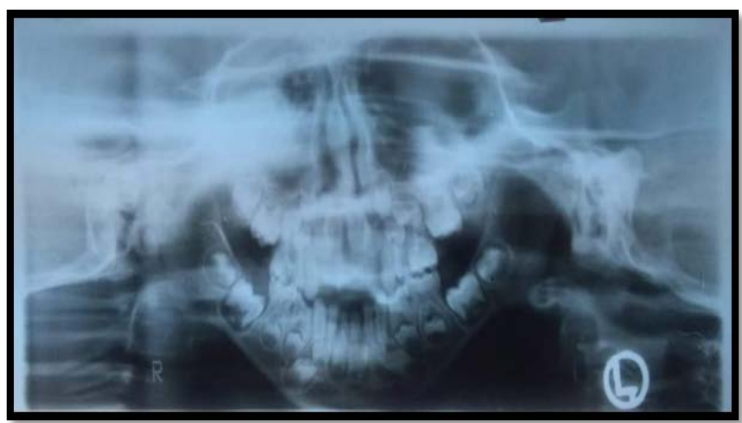

OPG showing mixed dentition, developing tooth buds, multiple root stumps and multiple carious teeth

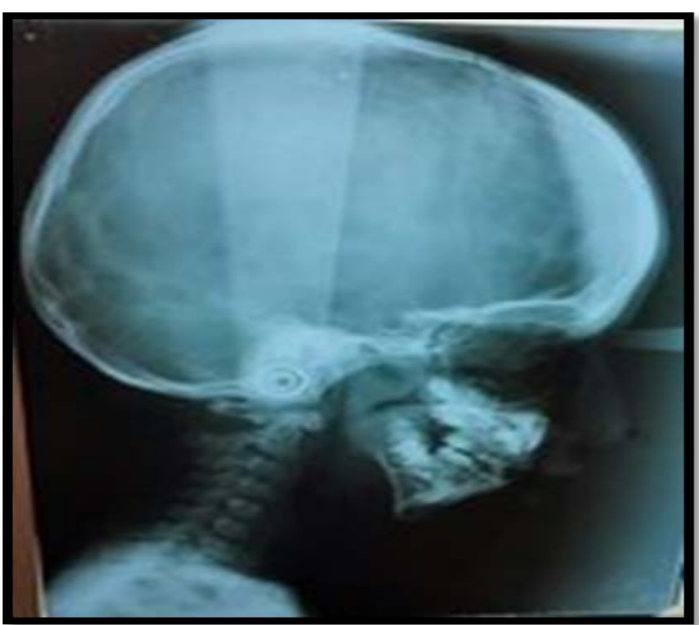




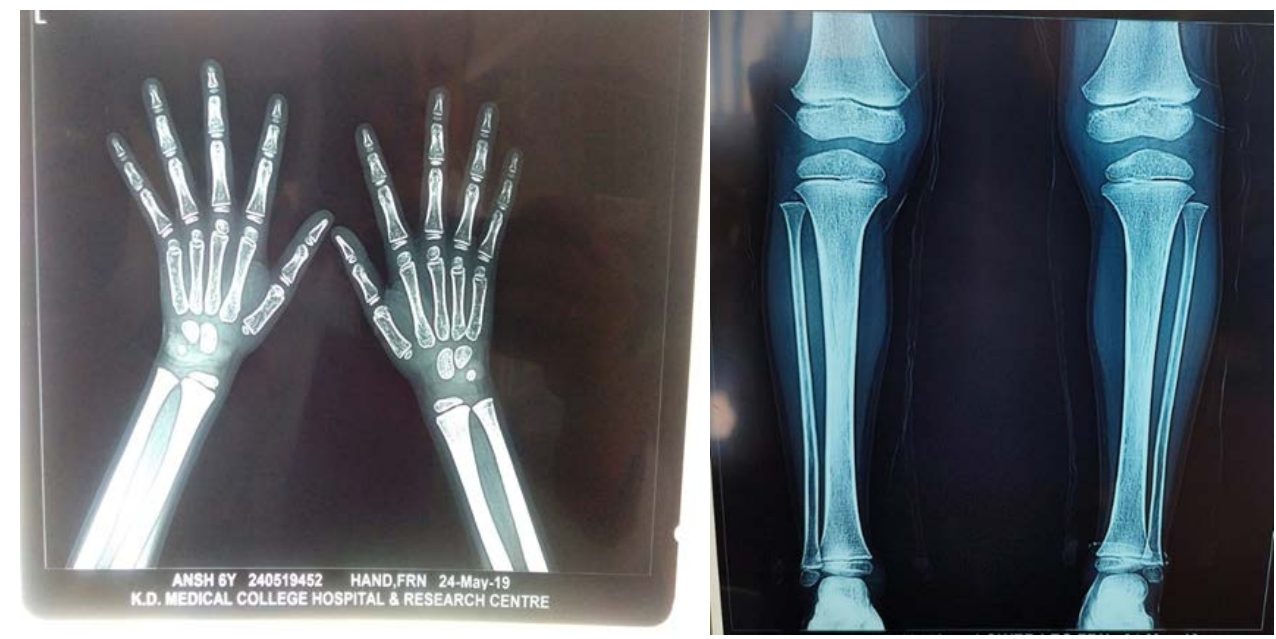

Hand wrist radiograph and lower leg radiograph appears normal.

\section{DISCUSSION}

TCS has an effect on the growth of facial bone and tissues. The severity of the syndrome differs significantly from person to person. The size, shape, and position of the ears, eyes, eyelids, cheekbones, and jaws are all affected by TCS. During pregnancy, there are many genes involved in the development of the face. TCS occurs when one of these genes changes (called a mutation). Scientists have identified three genes (known as TCOF1, POLR1C, and POLR1D) that relate to TCS, though there are others still unknown. In about half of cases, TCS is passed down genetically to a child from a parent (inherited). In other cases, the mutation happens randomly, without a known cause. There is no family disposition in the patient with Treacher Collin syndrome more than $60 \%$ patients. Our case doesn't show the positive family history suggesting familial mutation transfer in TCOF1 gene is absent. (6)

The craniofacial complex, which includes the skull, eyes, ears, nasal structures, face bones, and orodental tissues, is affected by the syndrome. The clinical presentation is usually bilaterally symmetrical and evident at birth. Our case, though bilaterally present, hypoplasia was more pronounced to the left side of the face.

Franceschetti has classified TCS into the following categories:
- Complete: classic major features

- Incomplete: less severe ear, eye, zygoma, and mandibular abnormalities

- Unilateral: affecting one side

- Abortive: only the lower lid pseudocoloboma and zygoma hypoplasia

- Atypical form: combined with other abnormalities not usually part of the typical syndrome. $(1,7,8)$

\section{Clinical features of TCS \\ I. Ophthalmic}

Features include antimongoloid slant of the palpebral fissures, coloboma (notching) and hypoplasia of the lower lids and lateral canthus, sparse, partially absent or totally absent lower eyelid cilia (particularly medial third). Minor features include loss of vision amblyopia, refractive errors, anisometropia, strabismus, hypertelorism, congenital cataracts and occasional microphthalmia/ anophthalmia, also lacrimal duct atresia, absence of puncta, narrowed tear ducts (dacryostenosis) may be evident.

\section{Orbits}

Orbital features include skeletal dysmorphism and hypoplasia with respect to lateral aspects.

\section{Otological abnormalities}

Anomalies of external ear include alteration in size, shape, and position [small, malformed ears (microtia) or rotated ears]. 
External auditory canal atresia, middle ear cavity ossicular deformities are also evident. Hypoplasia of the external auditory canals is present leading to conductive hearing loss upto $60 \mathrm{~dB}$ due to hypoplasia of the external auditory canals.

\section{Facial bone malformation}

Bilaterally symmetrical convex facial profile with hypoplasia of the malar bones and zygomatic complex (cardinal feature) is present.

\section{Maxilla and mandible}

Characteristically maxillary and mandibular hypoplasia is present. Also there is distalization of mandible with variable effects on temporomandibular joint (TMJ) and steep occlusal plane.

\section{Nose/mouth}

There is respiratory compromise along with maxillary hypoplasia (nasal passage constriction), mandibular micrognathia and retropositioned tongue (oropharyngeal and hypopharyngeal spaces obstruction). Other features include: prominent nose with nasal deformity, microstomia, Cleft palate with or without cleft lip and high-arched palate.

\section{Dental abnormalities}

Dental abnormalities include: malocclusion, tooth agenesis, enamel opacities, widely spaced teeth and skeletal open bite, bird-like facies and ectopic eruption of maxillary first molars

\section{Other minor manifestations}

Minor manifestations include preauricular hair displacement, airway abnormalities, tracheostoma, unilateral or bilateral choanal stenosis or atresia. Also there may be absence of parotid glands, cervical spine malformation, cryptorchidism, extremity malformation, renal anomalies, and congenital heart disease. Delayed motor or speech development may also be seen. $(1,9,10)$

\section{DIFFERENTIAL DIAGNOSIS}

- Nager's acrofacial dysostosis

- Milleracrofacial dysostosis

- Oculoauriculovertebral spectrum

- Goldenhar syndrome (11)

\section{Treatment plan and management of TCS}

1. Airway obstruction

- Distraction osteogenesis enables neonatal mandible advancement-relieves airway obstruction

- Airway stable-mandibular distraction delayed until early childhood

\section{Retrognathic mandible}

- Mandibular lengthening performed at 23 years or later

- Bone reconstruction (autogenous tissues) should precede soft tissue correction

- Before facial growth is complete-Chin augmentation + mandibular distraction

- Definitive orthognathic surgery-delayed until 16-18 years

- Bilateral sagittal ramus/maxillary segmental/Le Fort I osteotomy

\section{Nose/eyes/ear-late childhood}

- High-bridged nose-classical rhinoplasty

- Coloboma of the lower eyelid-Z-plasty

- Prosthetic auricular reconstruction and bone-assisted hearing aid (BAHA) placement

\section{Cleft palate}

- Palatoplasty-as early as the first year of life

- Speech therapy-evaluation by otolaryngologist

\section{Dental correction}

- Orthodontic and dental treatmentundertaken once definitive skeletal correction is finalized. (1)

Orthodontics in conjunction with orthognathic surgery allows us to correct jaw and jaw growth defects. These patients usually have no teeth or misplaced teeth. In this way, Orthodontics can assist improve 
bite and intercuspidation in this way. However, because of the multiple surgical treatments example extractions and implant placement may be required in many situations, as the various surgical interventions associated with bone deficiency make any damage to the roots of the tooth more likely. Oral hygiene can be an issue for some of these patients. Dalben, et al. demonstrated a high rate of plaque resulting from poor tooth brushing. This leads to a high frequency of restorative needs. In this context, there is a great need to establish a regular dental follow-up program for these patients. Caregivers should educate patients about the need of daily oral hygiene and encourage them to take charge of their own care at home (5)

\section{CONCLUSION}

Treacher Collin syndrome affects each patient differently. Surgical procedures improved several of the disease's anomalies. A proper planning and discussing making can produce excellent results for patient. When Treacher Collin syndrome is confirmed by clinical radiography and patient and parent history, it is critical to pay attention to psychosocial needs. (6)

\section{Acknowledgement: None}

\section{Conflict of Interest: None}

\section{Source of Funding: None}

\section{REFERENCES}

1. Thomas P, Krishnapillai R, et al. Treacher Collins Syndrome: A Case Report and Review of Literature. Oral Maxillofac Patho J 2019; 10(2):90-94.

2. Martelli-Junior H, Coletta RD, Miranda RT, Barros LM, Swerts MS, Bonan PR. Orofacial features of Treacher Collins syndrome. Med Oral Patol Oral Cir Bucal. 2009 Jul 1;14 (7):E344-8

3. Shete P, Tupkari JV, Benjamin T, Singh A. Treacher Collins syndrome. J Oral Maxillofac Pathol 2011;15:348-51.

4. Khodadady E, Dehghan Z. Treacher Collins Syndrome: A Case Report and Review of Literature. J Pediatr Rev. 2019; 7(1):45-54. http://dx.doi.org/10.32598/jpr.7.1.45

5. Duque $\mathrm{C}$ and Lopes Cardoso, Treacher Collins syndrome and implications in the oral cavity. Clin Res Trials, 2019.

6. Singh G, Garg A, Awana RS, Kumar A, Agarwal A, Walia N, Singh H. Treacher Collins Syndrome: A Case Report and Review of Literature. Int J Oral Health Med Res 2017;4(3):67-69.

7. Gorlin RJ, Pindborg JJ. Syndromes of the head and neck. Mandibulofacial dysostosis. New York: Thee Blackiston Division, McGraw-Hill; 1964. pp. 346-353.

8. Hertle RW, Ziylan S, et al. Ophthalmic features and visual prognosis in the Treacher Collins syndrome. $\mathrm{Br} \mathrm{J}$ Ophthalmol. 1993; 77:642-645. DOI: 10.1136/bjo.77.10.642.

9. Fernandez AO, Ronis ML. The TreacherCollins Syndrome. Arch Otolaryngol. 1964;80:505-520. DOI: 10.1001/archotol.1964. 00750040519006.

10. Posnick JC. Treacher Collins syndrome: perspectives in evaluation and treatment. $\mathrm{J}$ Oral Maxillofac Surg 1997 Oct 1;55(10):1120-1133. DOI: 10.1016/S02782391(97)90294-9.

11. Mohan RP, Verma S, Agarwal N, Singh U. Treacher Collins syndrome: a case report. BMJ Case Rep. 2013 May 24;2013: bcr2013009341. doi: 10.1136/bcr-2013009341. PMID: 23709540; PMCID: PMC3669902.

How to cite this article: Kumari N, Gopa Kumar $\mathrm{R}$ Nair, Mohan $\mathrm{V}$ et.al. Treacher collins syndrome: a case report. International Journal of Research and Review. 2021; 8(11): 100-105. DOI: https://doi.org/10.52403/ijrr.20211113 